\section{P584 FACTORS PREDICTING LIFETIME SEXUAL EXPERIENCE AMONG RURAL, RESERVATION-BASED NATIVE AMERICAN YOUTH}

'Lauren Tingey*, ${ }^{2}$ Rachel Chambers, ${ }^{2}$ Anne Rompalo, ${ }^{2}$ Anna Beach, ${ }^{2}$ Laura Melgar, ${ }^{2}$ Summer Rosenstock, ${ }^{3}$ Angelita Lee. ${ }^{1} J o h n s$ Hopkins University, Johns Hopkins Center for American Indian Health, Baltimore, USA; ${ }^{2} J o h n s$ Hopkins Center for American Indian Health, Baltimore, USA; ${ }^{3}$ Johns Hopkins Center for American Indian Health, Whiteriver, AZ, USA

\subsection{6/sextrans-2019-sti.655}

Background Early sexual initiation is a risk factor for sexually transmitted infection and unintended pregnancy. Native American youth initiate sex earlier than other U.S. youth contributing to current inequalities in sexual health. Identifying factors that predict lifetime sexual experience among Native youth can inform the development of primary prevention programming to delay sexual initiation and improve sexual health outcomes in this population.

Methods We analyzed cross-sectional data from 558 Native youth ages 11-19 from a rural, reservation-based community. Multivariate logistic regression models were used to estimate associations between lifetime sexual experience (vaginal and/or anal sex) and independent variables across eight categories: sociodemographic, knowledge, attitudes/perceptions, beliefs, intentions, skills, behaviors, and theoretical constructs.

Results The sample was $51.6 \%$ female, mean age 13.4 years $(S D=1.9)$; and $8.0 \%$ were sexually experienced. In our final model, older age $(\mathrm{OR}=2.04 ; \mathrm{p}<0.0001)$ and identifying as transgender $(\mathrm{OR}=35.3 ; \mathrm{p}=0.019)$ predicted lifetime sexual experience. The notion that sometimes sex just happens $(\mathrm{OR}=0.56 ; \mathrm{p}=0.01)$, and having condom use self-efficacy $(\mathrm{OR}=0.47, \mathrm{p}=0.026)$ were negatively associated with lifetime sexual experience. Youth who intended to have sex in the next 6 months were more likely to be sexually experienced $(\mathrm{OR}=3.18 ; \mathrm{p}<0.0001)$. Recent substance use including having smoked cigarettes $(\mathrm{OR}=4.38, \mathrm{p}=0.048)$, and having smoked marijuana in the past 3 months $(\mathrm{OR}=6.48, \mathrm{p}=0.002)$ predicted lifetime sexual experience.

Conclusion Results provide direction for future programming. Programs focusing on intentions to have sex while cultivating skills to promote condom use, in addition to being delivered stratified by age, may have the greatest impact. Substance use was a driving factor in sexual initiation; thus, sexual health education programs should simultaneously target substance use prevention. That identifying as transgendered predicted sexual experience is notable: despite research indicating transgendered youth of other ethnicities have heightened risk for negative sexual health outcomes, little research has been conducted with transgendered Native youth.

Disclosure No significant relationships.

\section{P585 INUIT COMMUNITY READINESS: ADAPTING THE COMMUNITY READINESS MODEL WITH INUIT COMMUNITIES FOR HIV PREVENTION}

\footnotetext{
${ }^{1}$ Audrey Steenbeek*, ${ }^{2}$ Tracey O'Hearn, ${ }^{3}$ Jenny Rand, ${ }^{3}$ Janet Curran, ${ }^{4}$ Marni Amirault, ${ }^{5}$ Diane Sammurtok, ${ }^{4}$ Renee Masching, ${ }^{5}$ Igah Sanguya, ${ }^{2}$ Ashlee Pigford, ${ }^{6}$ Barbara Plested. ${ }^{1}$ Dalhousie University, Nursing, Halifax, Canada; ${ }^{2}$ Pauktuutit, Ottawa, Canada; ${ }^{3}$ Dalhousie University, Nursing, Halifax, Canada; ${ }^{4}$ Canadian Aboriginal AIDS Network, Halifax, Canada; ${ }^{5}$ Nunavut Health and Social Services, Arviat, Canada; ${ }^{6}$ Colorado State University, Fort Collins, USA
}

10.1136/sextrans-2019-sti.656
Background With the highest rates of STIs in Canada, high mobility between North and South and a lack of adequate screening for STBBIs, it is possible that Inuit communities could face an HIV epidemic. If no action is taken to scale up prevention efforts, an epidemic in Inuit communities in the North could soon be a reality. Therefore, gauging an Inuit community's level of readiness to develop and participate in community-based HIV prevention, education, screening, and ensuring approaches are culturally relevant is imperative.

Methods This current research project builds directly on priorities outlined by Inuit stakeholders, and is facilitated through strong partnerships between the three communities (Kugluktuk, Arviat, and Clyde River Nunavut), Pauktuutit Inuit Women of Canada, the Canadian Aboriginal AIDS Network, and Dalhousie University. The goal of this research project is to engage Inuit communities and organizations in adapting, piloting and using the Community Readiness Model (CRM) to improve readiness to engage in HIV-modalities at the community level. This presentation will outline the community engagement and integrated knowledge translation processes, progress to date, and next steps for this community-based research project.

Results This project has adopted Inuit Qaujimajatuqangit (IQ) as a framework, which supports personal wellness through a collective cultural sense of health. Consultations with the project advisory committee (Canadian Inuit HIV/AIDS Network (CIHAN)), Community Health Representatives from three respective Nunavut communities and the research team were held November 2015. We are working collaboratively to: (1) adapt the CRM; (2) ensure it is Inuit-specific; (3) pilot the adapted tool; and (4) determine the applicability of this tool. Representatives from Nunatsiavut, Nunavik and Inuvialuit will also be mentored on how to use the adapted CRM.

Conclusion By engaging knowledge users and communities, this project will address HIV prevention in Inuit communities by identifying factors that impact readiness for HIV interventions.

Disclosure No significant relationships.

\section{P586 IKAJURNIQ: AN INUIT CASCADE OF CARE FRAMEWORK FOR SEXUALLY TRANSMITTED AND BLOOD BORNE INFECTIONS}

Savanah Ashton, Sipporah Enuaraq. Pauktuutit Inuit Women of Canada, Ottawa, Canada

\subsection{6/sextrans-2019-sti.657}

Background Introduction: Inuit in Canada are experiencing high rates of sexually transmitted and blood-borne infections (STBBIs). While there is limited Inuit-specific statistical information, we know that chlamydia, gonorrhea and syphilis rates in Inuit regions are high. A central approach to reducing STBBIs among Inuit communities is the development of effective methods to increase the number of Inuit being tested, diagnosed and treated before they spread infection to others.

Methods At its inaugural meeting in November 2017, the National Inuit Sexual Health Network, made up of sexual health experts and community representatives, developed an Inuit-specific STBBI Cascade of Care framework called Ikajurniq - meaning "the act of helping". 